\title{
Prevalencia de genotipos del papiloma virus humano en mujeres de la provincia del Azuay, Ecuador
}

\author{
José A. Cabrera V., Oswaldo J. Cárdena H., Manuel A. Campoverde C., José I. Ortiz S. \\ Grupo de Investigación en Biología Molecular, Facultad de Ciencias Médicas, Universidad de \\ Cuenca, Av. 12 de Abril s/n Sector El Paraíso, Cuenca, Ecuador.
}

Autor para correspondencia: jose.cabrerav@ucuenca.edu.ec

Fecha de recepción: 26 de febrero de 2015 - Fecha de aceptación: 18 de mayo de 2015

\begin{abstract}
RESUMEN
Los principales objetivos de la investigación fueron detectar en función con la edad, la prevalencia de los genotipos de alto y bajo riesgo oncogénico de virus del papiloma humano (VPH) en muestras cervicales de las mujeres en los catorce cantones de la provincia de Azuay. El proyecto abarcó el diagnóstico histopatológico de las lesiones cervicales intraepiteliales y la relación de los genotipos encontrados, con los factores de riesgo y las vacunas existentes que se utilizan como medida de prevención de cáncer de cuello uterino. Fueron examinadas muestras de frotis cervicales de una población aleatoria de 500 mujeres con la prueba de Papanicolaou (Pap), usando la reacción en cadena de la polimerasa en tiempo real (PCR). El estudio reveló una prevalencia de VPH de 25.6\%; $4.8 \%$ genotipos oncogénicos de bajo riesgo y el $20.8 \%$ genotipos oncogénicos de alto riesgo respectivamente, y sólo en el grupo de edad de 20 a 29 años, una significativa prevalencia mayor de los genotipos de alto riesgo 31 y $66(\mathrm{p}<0.05)$. Las células escamosas atípicas de significado indeterminado (ASCUS) representan el 7\% y la lesión intraepitelial escamosas de bajo grado (LIEBG) $1.8 \%$. Por otra parte no se identificaron lesiones escamosas intraepiteliales de alto grado. De la población encuestada $2.8 \%$ de las mujeres poseen genotipos virales que son tratables por las vacunas distribuidas por el Ministerio de Salud Pública (MSP).
\end{abstract}

Palabras clave: VPH, PCR, genotipo, riesgo oncogénico, muestra cervical.

\begin{abstract}
The main objectives of the research were to detect as a function of age the prevalence of high- and low-risk oncogenic Human Papillomaviruses (HPV) in cervical samples of woman in the fourteen districts of the province of Azuay. The project encompassed the cytopathological diagnosis of intraepithelial cervical lesions and the risk factors of the genotypes found were related with existing vaccines which are used as a preventive measure of cervical cancer. Cervical smear samples from a random population of 500 women were screened with the Papanicolaou (Pap) test using real-time polymerase chain reaction (PCR). The study revealed a prevalence of HPV of $25.6 \%$, respectively $4.8 \%$ low-risk oncogenic genotypes and $20.8 \%$ high-risk oncogenic genotypes, and only in the 20-29 age group a significant higher prevalence of the high-risk genotypes 31 and $66(\mathrm{p}<0.05)$ was observed. Atypical squamous cells of undetermined significance (ASCUS) represent 7\% and the lowgrade squamous intraepithelilial lesion (LSIL) 1.8\%. Furthermore no high-grade squamous intraepithelilial lesions were identified. Of the surveyed population $2.8 \%$ of the women possess viral genotypes which are treatable by the vaccines distributed by the Ministry of Public Health (MSP).
\end{abstract}

Keywords: HPV, PCR, genotype, oncogenic risk, cervical sample. 


\section{INTRODUCCIÓN}

En la última década se ha demostrado que el virus del papiloma humano (VPH) es la causa del cáncer cérvico-uterino, lo que ha conducido al desarrollo de nuevas estrategias diagnósticas, preventivas y educativas conducentes a disminuir el impacto de los factores de riesgo asociados que condicionan la infección, así como también a la administración de vacunas contra el VPH. Las técnicas de biología molecular han permitido diferenciar genéticamente los virus de bajo riesgo y los de alto riesgo oncogénico que provocan el cáncer de cuello uterino. Constituye un problema de salud el no conocer la prevalencia de los genotipos del papiloma virus en las mujeres de los 14 cantones de la provincia del Azuay. La presente investigación, sobre los genotipos virales del VPH en las muestras cérvicouterinas, conduce a relacionar la presencia de estos virus con las lesiones benignas o malignas del cuello uterino, a fin de aplicar las medidas preventivas para evitar o disminuir la progresión de este cáncer en la población afectada.

El cáncer del cuello del útero es un grave problema de salud en el país y región. En los últimos diez años se ha incrementado la mortalidad por esta causa, realidad directamente vinculada a los escasos programas de detección oportuna y tratamiento de esta patología. La sociedad de lucha contra el cáncer en el "V Informe de Incidencia de Cáncer en el Cantón Cuenca" manifiesta que la incidencia del cáncer de cuello uterino in situ es de 3.9\% y del cáncer invasor de $17.5 \%$, representando la primera causa de cáncer en el cantón (SOLCA, 2007). Está comprobado que el virus del papiloma humano (VPH) es el responsable de la mayoría de cánceres cérvico-uterinos. Desde 1986 es posible determinar mediante pruebas de laboratorio de biología molecular, con la técnica de reacción en cadena de la polimerasa (PCR) los genotipos de bajo y alto riesgo oncogénico; estos últimos tienen una alta probabilidad de desarrollar el cáncer cérvico-uterino.

El VPH es un virus que pertenecen al género A de la familia de los Papovaviridae, se clasifican en genotipos por las características de su ADN. Contienen una doble hebra de ADN de 7800 a 7900 pares de bases, el virión mide 45-55 nm y tiene una cápside icosaédrica compuesta por 72 capsomeros. Por tener un genoma de tamaño limitado no codifica enzimas para la replicación viral, depende por lo tanto de la estructura genética de la célula huésped para reproducirse. Prefiere el epitelio inmaduro del cérvix (células metaplásicas y células del estrato basal o de reserva) por lo que se expresa en la zona de transformación el cuello uterino de mujeres jóvenes, y una vez infectadas, con su proliferación favorecen la progresión de la infección. El genoma viral está organizado en tres regiones principales: dos codificadoras de proteínas (regiones precoz y tardía) y una no codificante pero sí reguladora (Biocáncer Research Journal, 2010a).

El origen de este virus parece ser africano, desde los primates pre-humanos, con la consiguiente propagación mundial a las diferentes razas humanas, creando una simbiosis entre patógeno y huésped. (Monk \& Wiley, 2003). Está comprobado que la infección por el VPH es una de las más frecuente infecciones de transmisión sexual y actualmente se considera a este virus como el agente causal del carcinoma cérvico-uterino (Kolnikova et al., 2014). Se ha detectado ADN de VPH en el $98 \%$ de carcinomas de cervix. Los genotipos 16 y 18 son los que presentan un riesgo de 11-16.9 veces mayor de desarrollar de forma rápida una lesión intraepitelial de alto grado. Estos producen las proteínas E6 y E7, las cuales se unen a los genes supresores tumorales p53 y pRb respectivamente, inhibiendo su función. Cuando p53 y pRb no pueden realizar su función, por acción del VPH, las lesiones del ADN de las células epiteliales cervicales no se reparan. Por tanto, la acción del virus altera las células, induciendo su transformación desde células normales a células displásicas, y posteriormente a células invasivas tumorales (Biocáncer Research Journal, 2010b). Se ha descubierto más de 200 genotipos de VPH y de acuerdo a su potencial oncogénico están divididos en genotipos de alto riesgo: 16, 18, 31, $33,35,39,45,51,52,56,58,59,66,68$, que tienen asociación con lesiones intraepiteliales y con el cáncer uterino, y los genotipos de bajo riesgo: $6,11,42,43,44$, relacionados con lesiones benignas llamadas condilomas (De Guglielmo et al., 2008). Los expertos concuerdan que solamente 80 tipos de VPH se han secuenciado y escrito oficialmente (Monk \& Wiley, 2003). Los genotipos del VPH se clasifican en cutáneos y en mucosos; estos últimos se transmiten por contacto sexual y son los siguientes $(6,11,13,32,16,18,31,33,35,45,51,52,56,30,39,34,58,40,42,43,54,55,57,59)$ (Rocha, 2014). La existencia de muchos genotipos de VPH se debe a que son virus ADN, que para 
replicarse necesitan de los componentes de la estructura celular de la célula huésped, en especial del núcleo, por lo que se producen variaciones genéticas grandes. Los VPH poseen un genoma organizado en forma muy especial, pues está constituido por los denominados "marcos de lectura abiertos", en el que se producen una sobre posición de genes, lo cual obedece a que el genoma viral se encuentra encriptado con múltiples mensajes genómicos. También aparecen los nombrados genes "E" (genes tempranos), que codifican para proteínas tempranas al momento de la infección celular; y los genes "L" (genes tardíos) que codifican las proteínas estructurales que formarán parte de la partícula viral. De los genotipos existentes, 30 infectan al tracto genital; los virus que infectan mucosas y los que infectan epitelios no son los mismos, lo cual tiene una implicancia clínica y epidemiológica importante, pues una verruga de la piel no es capaz de transmitir el virus al tracto genital. Existe una variación genética del genotipo, pero también de variantes genéticas, lo que plantea el hecho de que diferentes virus producen diferentes infecciones y defectos dentro de la célula que infectan (Ojeda, 2010).

Se han identificado factores de riesgo para el cáncer del cuello uterino y son los siguientes: infección por el virus del papiloma humano, tabaquismo, inmunosupresión, infección con clamidia, alimentación con pocas frutas y verduras, sobrepeso, uso prolongado de anticonceptivos orales, uso de un dispositivo intrauterino, múltiples parejas sexuales, muchos embarazos a término, embarazo antes de los 17 años, pobreza y antecedente familiar de cáncer de cuello uterino (Américan Cancer Society, 2015). Los factores de riesgo predominantes para la infección por el VPH genital en las mujeres jóvenes están relacionados no sólo con sus propios comportamientos sexuales, sino también con los de su pareja (Burk et al., 1996). Cuando la mujer es infectada por el VPH, puede no manifestar síntomas o signos y, en muchas personas, no llega a causar problemas de salud, sino que el virus es eliminado por el sistema inmune del organismo. Sin embargo, cuando la infección por VPH no se cura, y dependiendo del tipo de virus involucrado, puede provocar desde verrugas genitales, hasta diversos tipos de cáncer. Las verrugas genitales, pueden ser de diversos tamaños -planas o elevadas-, observables a simple vista. Si no se sigue ningún tratamiento, con el tiempo estas verrugas pueden desaparecer, permanecer inalterables, o crecer y multiplicarse. En Sao Paulo, Brasil, se investigó a 1425 mujeres de bajos ingresos que asisten a un programa de salud materno-infantil; el 25\% fueron positivos para VPH; $1.3 \%$ de nuevas infecciones por mes, con un $38 \%$ de positividad acumulada después de 18 meses; sólo el 35\% se mantenía infectado después de 12 meses. La tasa de depuración mensual fue mayor para los tipos no oncogénicos que para los oncogénicos. Las duraciones de infección media fueron 8.2 y 13.5 meses para no oncogénico y oncogénico respectivamente. La incidencia de la infección por VPH entre las mujeres inicialmente negativas es de un $60 \%$ en un período de seguimiento de 5 años (Baseman \& Koutsky, 2005). Algunos estudios indican que la edad de la mujer no afecta la duración media de los tipos oncogénicos (13-14 meses), sin embargo algunas investigaciones indican que las infecciones de tipo oncogénico duran más tiempo (10.2 meses) entre las más jóvenes que en las mujeres de más edad (5.6 meses). Investigaciones de cohorte demuestran que la infección por VPH es principalmente transitoria e intermitente (Franco et al., 1999). Estudios en Latinoamérica indican que la incidencia de virus de alto riesgo es mayor que los de bajo riesgo $(5,0$ vs. 2,0). Las infecciones con genotipos de alto riesgo duran más tiempo que las infecciones con los de bajo riesgo (14.8 vs 11.1 meses); se ha observado un primer pico de mayor prevalencia de la infección alrededor de los 20 años y un segundo pico entre 45 a 50 años (Munoz et al., 2004). La mayoría de las mujeres jóvenes con una prueba de VPH positiva se convertirá en negativa dentro de un período de 24 meses. Pruebas positivas persistentes con los tipos de VPH oncogénicos representan un riesgo significativo para el desarrollo de lesiones intraepiteliales de alto grado (HSIL) (Moscicki et al., 1998). La prevalencia del VPH en los cinco continentes, determinada mediante meta- análisis fue del 11,7\% (intervalo de confianza del 95\%, 11.6-11.7\%). Las mayores prevalencias se encuentran en África subsahariana (24\%), Europa del Este (21.4\%) y América Latina (16.1\%). La distribución de virus por edad presenta un primer pico en $<25$ años y un rebrote en edades más avanzadas superiores a 45 años. Los 5 genotipos más comunes en todo el mundo fueron VPH-16 (3.2\%), 18 (1.4\%), 52 (0.9\%), $31(0.8 \%)$, y el $58(0.7 \%)$ (Bruni et al., 2010). En Brasil, la prevalencia del VPH en la población femenina generalmente oscila desde 21 hasta 48\%, con los tipos de VPH de alto riesgo que se encuentran en 48 a 53\% (Fedrizzi, 2011). En Santa Elena Guayas-Ecuador 24.2\% (Brown et al., 
2009); en la ciudad de Quito-Ecuador el 67.7\% (González-Andrade \& Sánchez, 2009), en CuencaEcuador el 37.1\% (SOLCA, 2009).

Los métodos moleculares que detectan la presencia de HPV tienen como principio la amplificación específica del ADN viral; entre estos métodos está la prueba de captura de Híbridos, la reacción en cadena de la polimerasa (PCR); una variante de este último es la PCR en Tiempo Real. Se aplican estrategias para prevenir la infección por el VPH, como las vacunas contra los genotipos 6, 11, 16 y 18; educación sexual, reducción de las infecciones de transmisión sexual mediante el tratamiento, reducción del número de parejas sexuales; disminuir la eficiencia de la transmisión utilizando barreras físicas, como los condones, que pueden reducir el riesgo de enfermedades asociadas con este virus (por ejemplo, verrugas genitales y cáncer de cuello uterino). El tratamiento de las lesiones causadas por VPH depende de la severidad y extensión de la misma. Las lesiones de bajo grado pequeñas son tratadas con crioterapia, mediante esta técnica las células infectadas son destruidas por congelamiento. Cuando las lesiones son extensas, deben ser tratadas con electrocirugía, esta terapia involucra el uso de un asa diatérmica. El éxito del tratamiento es muy alto, el tejido cicatriza eficazmente $\mathrm{y}$, al ser una técnica ablativa conservadora, no se compromete la capacidad reproductiva de la paciente tratada. Las lesiones más extensas requieren de un tratamiento más agresivo, para ellas se utiliza la terapia con rayo laser que solo elimina las células potencialmente infectadas por el VPH, sin dañar tejidos vecinos. Las lesiones cervicales de alto grado deben ser eliminadas por métodos quirúrgicos más agresivos, como el cono cervical. Sin embargo esto no es aplicable cuando se detecta un cáncer invasor, en este caso la histerectomía (parcial o total dependiendo de las características de la paciente y de su tumor) es la alternativa quirúrgica empleada. Los cánceres avanzados, en los cuales la cirugía ya no es aplicable, son tratados con radioterapia y/o quimioterapia (Rocha, 2014).

El cáncer uterino es un problema sanitario relevante en los países subdesarrollados; a nivel mundial se presentan cerca de 500,000 nuevos casos, con una tasa de incidencia de 44.2 por 100,000 mujeres; el $80 \%$ de estos casos se encuentran en África, América Central, y América del Sur, en donde los sistemas de salud siguen siendo ineficientes y/o ineficaces. Anualmente en el mundo mueren 231,000 mujeres a causa de esta enfermedad, que representa la segunda en frecuencia en la población femenina a nivel mundial (Deluca et al., 2007).

Para determinar la prevalencia de los genotipos del VPH en las muestras cérvico-uterinas de 500 mujeres con vida sexual, de 17 a 50 años, que residen en los 14 cantones de la provincia del Azuay, su relación con la edad, factores de riesgo y con los genotipos que evitan las vacunas utilizadas contra este virus, se utilizó el método epidemiológico, observacional de corte transversal, con una muestra aleatoria y estratificada. Se eligió este método de investigación transversal ya que la identificación de los genotipos del papiloma virus se hizo en un tiempo determinado de ocho meses, y este método era el más adecuado para este tipo de investigación. El carácter de aleatorio, permite que los resultados sean extrapolados a toda la población femenina con vida sexual, entre 17 a 50 años, que residen en la provincia del Azuay. Las razones por las que se utilizó este método fueron porque el estudio tiene carácter estadístico, demográfico, de tipo biológico y social, en donde se miden las variables en un período de tiempo de ocho meses. Este estudio, responde a la necesidad de determinar la prevalencia del VPH en las muestras cérvico-uterinas de las mujeres de la provincia del Azuay e identificar los genotipos benignos y malignos del virus, los factores de riesgo para la infección ya que existe una relación directa entre este virus y el cáncer cérvico-uterino, que representa un problema de salud de la región y del país en vista de su incremento en los últimos años. El control periódico de las mujeres expuestas a los factores de riesgo para la infección por VPH y por ende para el desarrollo de las lesiones intraepiteliales de bajo y alto grado, evitará o minimizará el desarrollo del cáncer cérvicouterino; se considera que una de las formas de control es la identificación de los genotipos del papiloma virus humano, mediante la PCR, considerada hoy en día como la prueba de oro en el diagnóstico del papiloma virus humano. La identificación de los genotipos del VPH encontrados en el cuello uterino de las mujeres de la provincia del Azuay, permitirá realizar un seguimiento de aquellas portadoras de genotipos malignos. Como es un estudio aleatorizado, los resultados de la investigación deben ser extrapolados a toda la población femenina de 17 a 50 años de la provincia del Azuay, información que debe ser considerada por la Dirección Zonal 6 de Salud para que se emprendan las medidas preventivas y curativas. La investigación además sirvió para relacionar el grado de eficacia 
de las dos vacunas existentes en nuestro medio para prevenir el cáncer del cuello uterino, con los genotipos encontrados en el estudio. La protección que daría la vacuna es baja ya que apenas lo haría al $2.8 \%$ de la población portadora de los genotipos 16 y 18 relacionados con el cáncer del cuello uterino.

El artículo inicia con un resumen estructurado que expone las ideas principales en torno al propósito de la investigación, los resultados y las conclusiones; una introducción con suficientes antecedentes y resultados de publicaciones para comprender y evaluar los resultados de la investigación, el diseño del estudio, la población, muestra, su entorno hospitalario, la intervención técnica (reacción en cadena de polimerasa) así como el análisis estadístico utilizado; los resultados, la discusión y conclusiones del trabajo investigativo; agradecimiento a las personas que colaboraron, y una amplia bibliografía sobre el tema.

\section{MATERIALES Y MÉTODOS}

Fue un estudio epidemiológico, observacional de corte transversal; el universo lo constituyeron 53.102 mujeres de 17 a 50 años, con vida sexual activa que residen en las zonas urbanas de los 14 cantones de la provincia del Azuay: Ponce Enríquez, Chordeleg, El Pan, Girón, Guachapala, Gualaceo, Nabón, Oña, Paute, Pucará, San Fernando, Santa Isabel, Sevilla de Oro y Sígsig. La muestra fue de 500 mujeres, obtenida de manera aleatoria, estratificada y ponderada de acuerdo a la población de cada cantón, datos que se disponen y pertenecen al último censo nacional (INEC, 2010); en los cantones se consideraron los sectores, manzanas y viviendas que conforman el área urbana, lugar de residencia de las mujeres en estudio. En las visitas domiciliarias se motivó la participación mediante una campaña de información sobre el cáncer cérvico-uterino, su relación con la infección por el papiloma virus y la necesidad de realizar el examen de Papanicolaou y la PCR para la detección oportuna del cáncer. Esta promoción se realizó por uno de los diarios de mayor circulación de la provincia, emisoras, y en el hospital o centro de salud cantonal respectivo. A las mujeres que libre y voluntariamente deseaban participar del estudio, se procedió a obtener su consentimiento firmado, se entregó una cita para la consulta ginecológica en las entidades de salud pública de la provincia, especificando el día, la hora y el nombre del médico que realizó la toma de la muestra cérvico-uterina. Los ginecólogos designados por la Dirección de Salud, procedieron a receptar la información de acuerdo con el formulario diseñado para la encuesta, en el que constan datos de filiación y las preguntas en relación con los factores de riesgo, para proceder luego a la toma de la muestra endo y exocervical. Para ello se utilizó materiales específicos DIGENE hc2 ADN Collection Device (USA) que preservan el material genético y la extracción del ADN mediante un kit comercial validado QIAGEN QIAamp ADN Mini Kit (Alemania). La toma de la muestra para PCR se realizó introduciendo el cepillo (citobrush) en el endocérvix entre 1 y $1.5 \mathrm{~cm}$ desde el orificio externo del cuello uterino hasta que las cerdas exteriores más cortas del cepillo toquen el exocérvix. Se hizo girar el cepillo tres veces en sentido contrario a las agujas del reloj. Terminado el procedimiento se retiró el cepillo del canal cervical y se introdujo la punta del mismo en el fondo del tubo, partiendo el bastoncillo en la marca del borde. Para el examen citopatológico se tomó la muestra con espátula de Ayre y cito brush, extendida en una placa que fue fijada para su preservación.

El diagnóstico y genotipado del Virus del Papiloma Humano se dio a través de la utilización del sistema SEEGENE-Anyplex II HPV28 detection (KOREA) por Reacción en Cadena de la Polimerasa en Tiempo Real Multiplex con el principio de Extensión y Escisión de Oligonucleótidos marcados (TOCE) misma que se menciona en varios artículos de investigación como la técnica de elección para este tipo de diagnóstico. Con esta tecnología detectamos nueve genotipos del VPH de bajo riesgo: 6, $11,40,42,43,44,54,61,70$ y 19 genotipos de alto riesgo: 16, 18, 26, 31, 33, 35, 39, 45, 51, 52, 53, $56,58,59,66,68,69,73,82$; ésta es una técnica cualitativa y cuantitativa que permite detectar en tres puntos de análisis cada genotipo gracias a mediciones parciales con curvas de melting (Tamay et al., 2013).

La detección fue semi-cuantitativa en tres puntos de análisis para cada subtipo, gracias a mediciones parciales con curvas del melting. El kit estuvo compuesto por dos sets de reactivos: el set 
A con blancos de ADN para amplificación simultánea de 14 tipos de alto riesgo; el Set B contiene blancos de ADN para amplificación de 5 tipos de alto riesgo y 9 tipos de bajo riesgo. El termociclador para tiempo real utilizado fue el CFX96 (BIO-RAD, USA). Para la identificación de las lesiones del cuello del útero, se realizó un estudio citológico de la muestra utilizando la técnica de tinción de Papanicolaou; para el reporte de los resultados se utilizó el Sistema Bethesda (Instituto Nacional del Cancer de los Estados Unidos, 2014).

La recolección y registro de la información así como los exámenes de laboratorio se realizó durante siete meses (marzo-septiembre). El análisis estadístico fue realizado por un experto utilizando el programa SPSS versión 17; se determinó frecuencias y porcentajes para identificar la prevalencia del VPH de acuerdo a la edad, el Chi-cuadrado para relacionar las variables, el Odds Ratio (OR) y la regresión logística para valorar la relación de los genotipos con los factores de riesgo.

\section{RESULTADOS}

Los resultados de la investigación se expresan considerando el diseño del estudio: epidemiológico, observacional de corte transversal.

El 47,6\%, de las 500 mujeres que participaron en el estudio, proceden de tres cantones: Gualaceo (21.4\%), Sígsig (13.8\%) y Paute (12.4\%); el $13.8 \%$ corresponde a las mujeres de los 11 cantones restantes (ver Fig. 1).

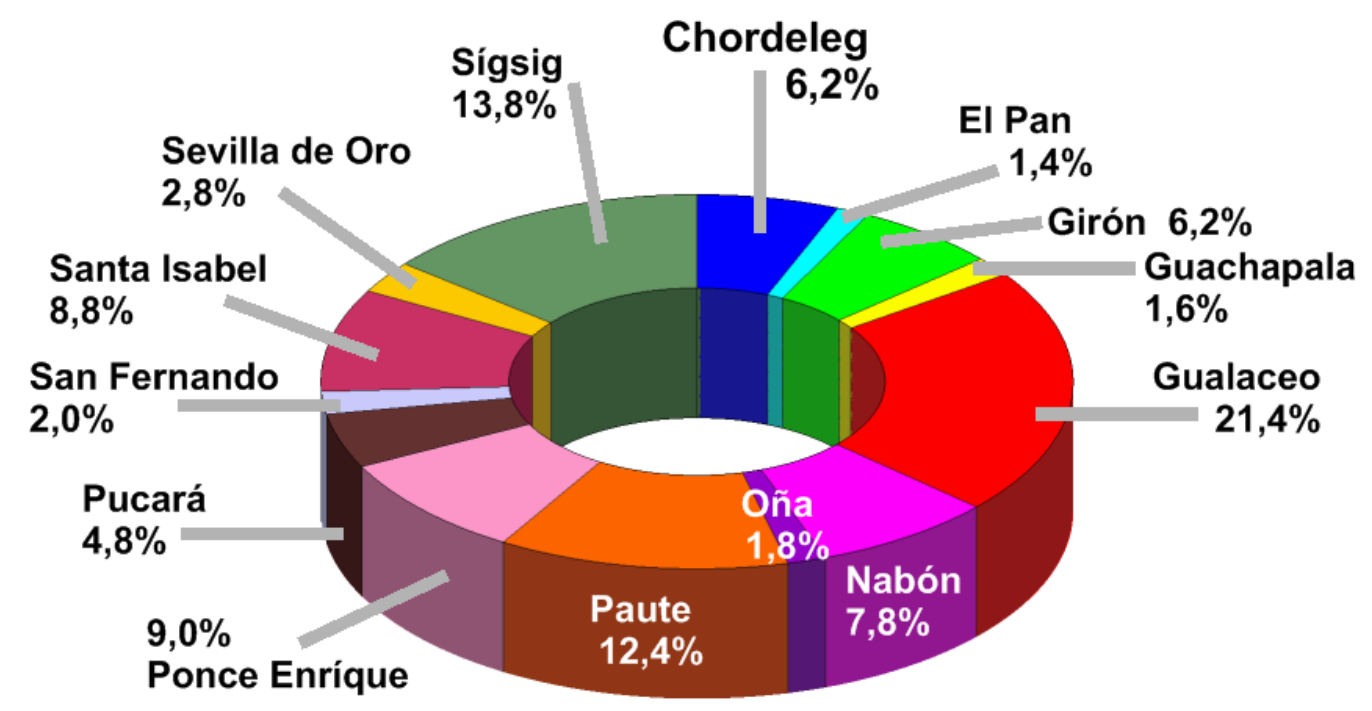

Figura 1. Porcentajes de las mujeres de los cantones del Azuay en las que se realizó la investigación.

Como se muestra en la Figura 2, el 44\% de la mujeres han alcanzado el segundo nivel de estudios formales; la tercera parte instrucción primaria; una de cada seis posee estudios superiores y muy pocas son analfabetas. La mayoría tienen muy bajos ingresos, menos de un salario básico, tanto personal (77.8\%) como en pareja (59\%). El 58\% son casadas, $17 \%$ solteras, en menor porcentaje viven en unión libre (15\%), divorciadas (8\%) y viudas (1\%). El 70\% tiene entre 30 a 50 años, el promedio de edad fue de 35 años. 
MASKANA, Vol. 6, No. 1, 2015

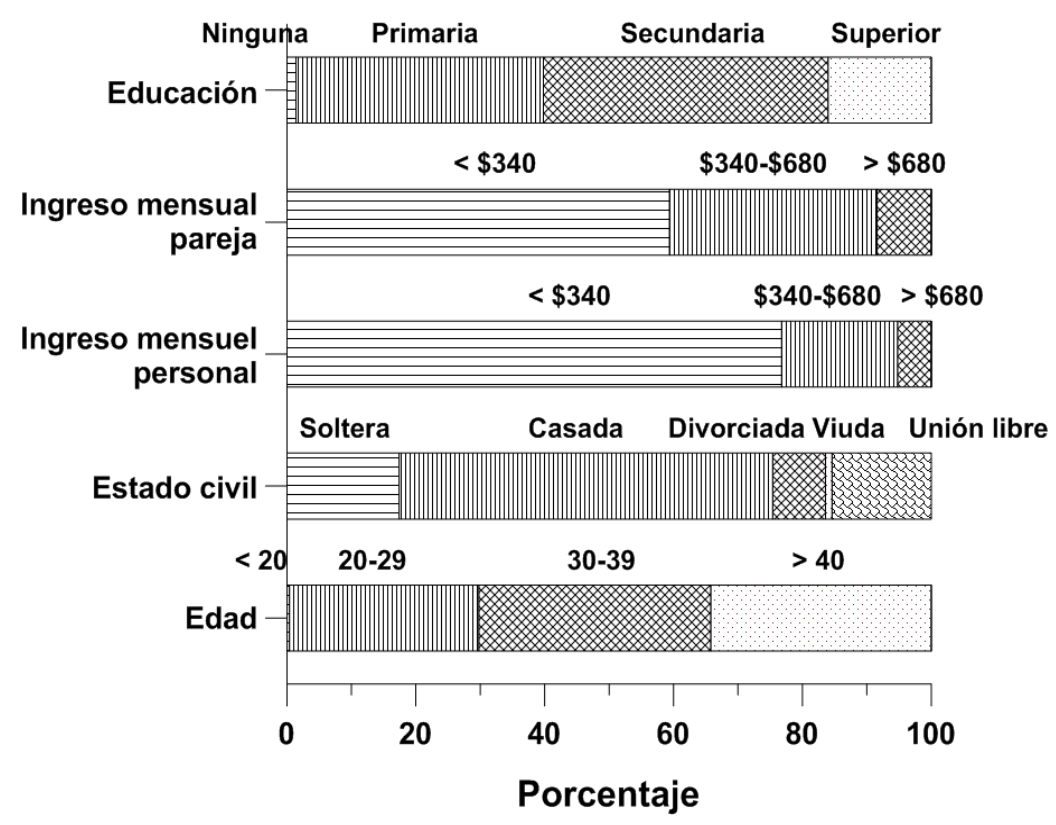

Figura 2. Características socioeconómicas: educación, ingreso mensual de la pareja y personal, estado civil y edad.

La prevalencia de los genotipos de alto riesgo oncogénicos (ver Fig. 3), identificados en las mujeres con vida sexual activa que residen en los 14 cantones de la provincia del Azuay, es de $20.8 \%$. En orden descendente se encuentran los genotipos 66 (3.2\%), 68 (2.8\%), $16(2.2 \%), 59(2 \%), 31$ $(1,8 \%), 39(1.6 \%), 33(1.4 \%), 53$ y $51(1.2 \%)$ y los demás con $1 \%$ o menos.

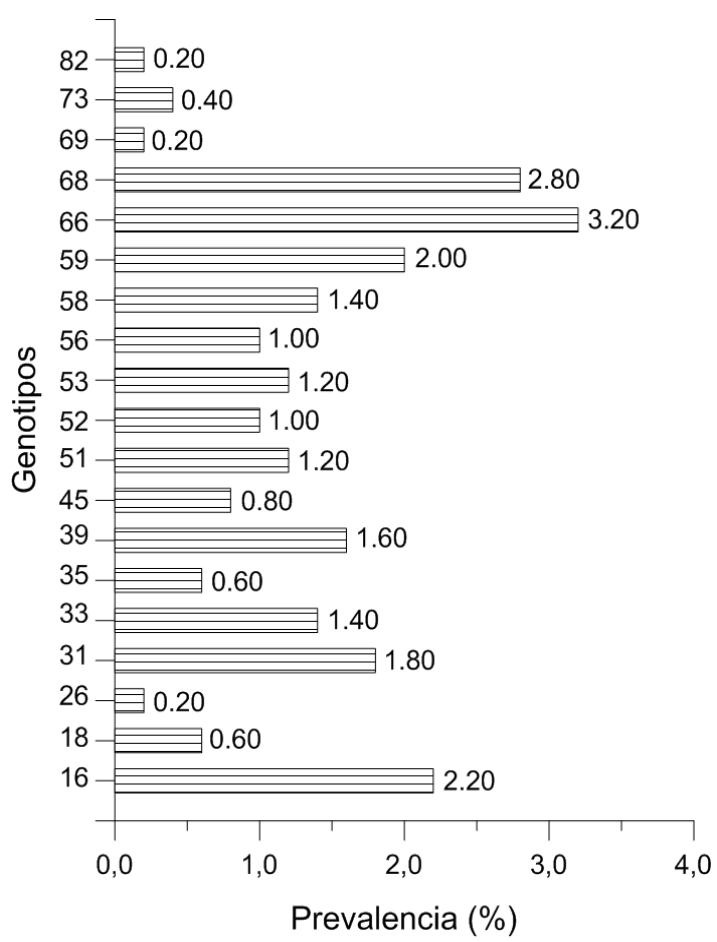

Figura 3. Prevalencia de los genotipos de alto riesgo oncogénico del papiloma virus humano en las mujeres de los 14 cantones de la provincia del Azuay. 


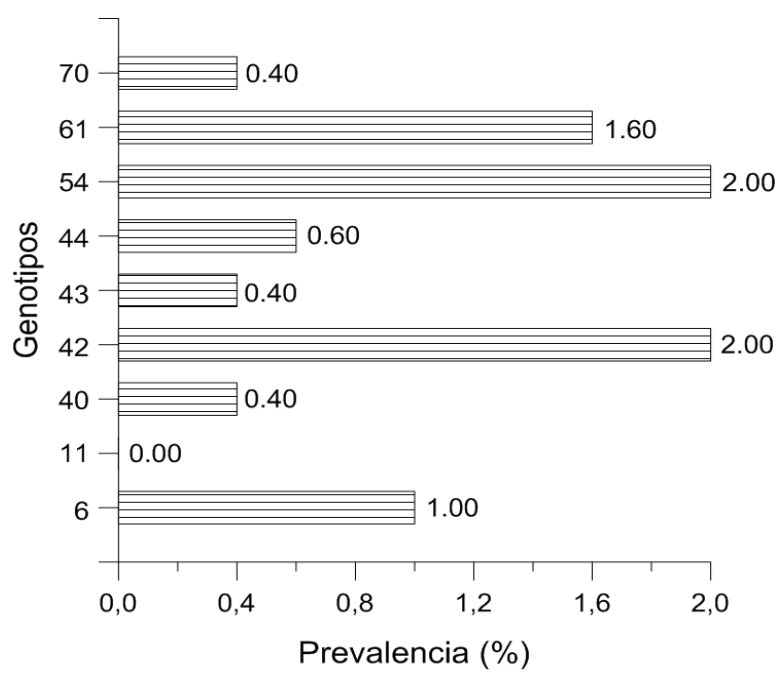

Figura 4. Prevalencia de genotipos de bajo riesgo oncogénico de virus del papiloma virus humano en las mujeres de los 14 cantones de la provincia del Azuay.

La prevalencia de los genotipos de bajo riesgo oncogénico en la población estudiada es del $4.8 \%$. Entre los genotipos de bajo riesgo oncogénico, como se representa en la Figura 4, la prevalencia en orden descendente es: el 42 y 54 , con el $2 \%$; el 61 , con $1.6 \%$; el 6, con $1 \%$; y con menos del $1 \%$ el 44 , 40, 43 y 70. No se encuentra el genotipo 11. Únicamente los genotipos de alto riesgo 31 y 66 se encuentran en mayor porcentaje en el grupo de 20 a 29 años, con una diferencia estadísticamente significativa $(\mathrm{p}<0.05)$, en relación con los otros grupos etarios.

Tabla 1. Prevalencia de los genotipos del virus de papiloma humano por cantones.

\begin{tabular}{|c|c|c|c|c|c|c|c|c|c|}
\hline \multirow{3}{*}{$\begin{array}{l}\text { Cantón } \\
\text { Chordeleg }\end{array}$} & \multicolumn{3}{|c|}{$\begin{array}{c}\text { Genotipos de VPH } \\
\text { de alto riesgo }\end{array}$} & \multicolumn{3}{|c|}{$\begin{array}{c}\text { Genotipos de VPH } \\
\text { de bajo riesgo }\end{array}$} & \multicolumn{3}{|c|}{ VPH Positivo } \\
\hline & \multirow{2}{*}{$\frac{\%}{16.13}$} & \multicolumn{2}{|c|}{ IC $95 \%$} & \multirow{2}{*}{$\frac{\%}{6.45}$} & \multicolumn{2}{|c|}{ IC $95 \%$} & \multirow{2}{*}{$\frac{\%}{22.58}$} & \multicolumn{2}{|c|}{ IC $95 \%$} \\
\hline & & 7.09 & 32.63 & & 1.79 & 20.72 & & 11.40 & 39.81 \\
\hline El Pan & 28.57 & 8.22 & 64.11 & 28.57 & 8.22 & 64.11 & 42.86 & 15.82 & 74.95 \\
\hline Girón & 12.90 & 5.13 & 28.85 & 3.23 & 0.57 & 16.19 & 12.90 & 5.13 & 28.85 \\
\hline Guachapala & -- & -- & -- & -- & -- & -- & -- & -- & -- \\
\hline Gualaceo & 29.91 & 22.05 & 39.15 & 6.54 & 3.20 & 12.89 & 32.71 & 24.55 & 42.06 \\
\hline Nabón & 15.38 & 7.25 & 29.73 & 17.95 & 8.98 & 32.67 & 30.77 & 18.57 & 46.42 \\
\hline Oña & 33.33 & 12.06 & 64.58 & -- & -- & -- & 33.33 & 12.06 & 64.58 \\
\hline Paute & 9.68 & 4.51 & 19.55 & 11.29 & 5.58 & 21.52 & 17.74 & 10.21 & 29.04 \\
\hline Ponce Enríquez & 26.67 & 15.96 & 41.04 & -- & -- & -- & 26.67 & 15.96 & 41.04 \\
\hline Pucará & 20.83 & 9.24 & 40.47 & 12.50 & 4.34 & 31.00 & 29.17 & 14.91 & 49.17 \\
\hline San Fernando & 30.00 & 10.78 & 60.32 & 10.00 & 1.79 & 40.42 & 30.00 & 10.78 & 60.32 \\
\hline Santa Isabel & 20.45 & 11.15 & 34.50 & 4.55 & 1.26 & 15.13 & 22.73 & 12.84 & 36.99 \\
\hline Sevilla de Oro & 14.29 & 4.01 & 39.94 & -- & -- & -- & 14.29 & 4.01 & 39.94 \\
\hline Sígsig & 18.84 & 11.35 & 29.61 & 10.14 & 5.00 & 19.49 & 27.54 & 18.39 & 39.05 \\
\hline Total & 20.80 & 17.10 & 24.15 & 7.80 & 5.76 & 10.49 & 25.60 & 21.97 & 29.60 \\
\hline
\end{tabular}

Como se muestra en la Tabla 1, unicamente en el cantón Oña hay una prevalencia de VPH de alto riesgo superior al 30\%; los cantones en los que se encontró prevalencias entre 20 a 30\% fueron San Fernando, Gualaceo, El Pan, Ponce Enriquez, Santa Isabel y Pucará; en los demás cantones 
encontramos valores inferiores a $20 \%$, siendo el cantón Paute el que presenta la menor prevalencia (9.68\%). Con relación a los genotipos de VPH de bajo riesgo, en el cantón El Pan se detectó la mayor prevalencia (28.57\%), le siguen Nabón, Pucará, Paute y Sigsig con prevalencias entre 10 a $20 \%$.

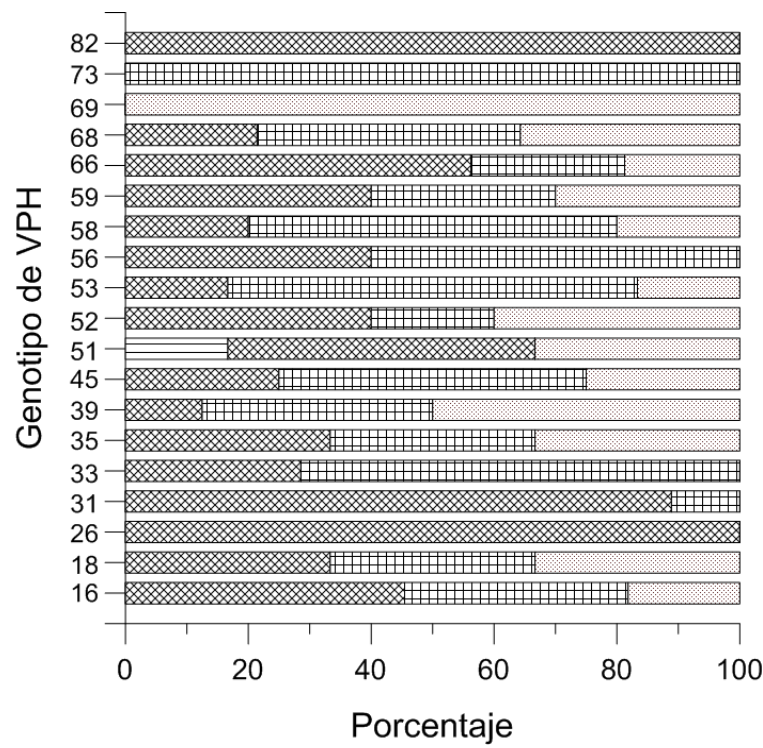

Figura 5. Relación de los genotipos de alto riesgo del papiloma virus humano con grupos de edad.

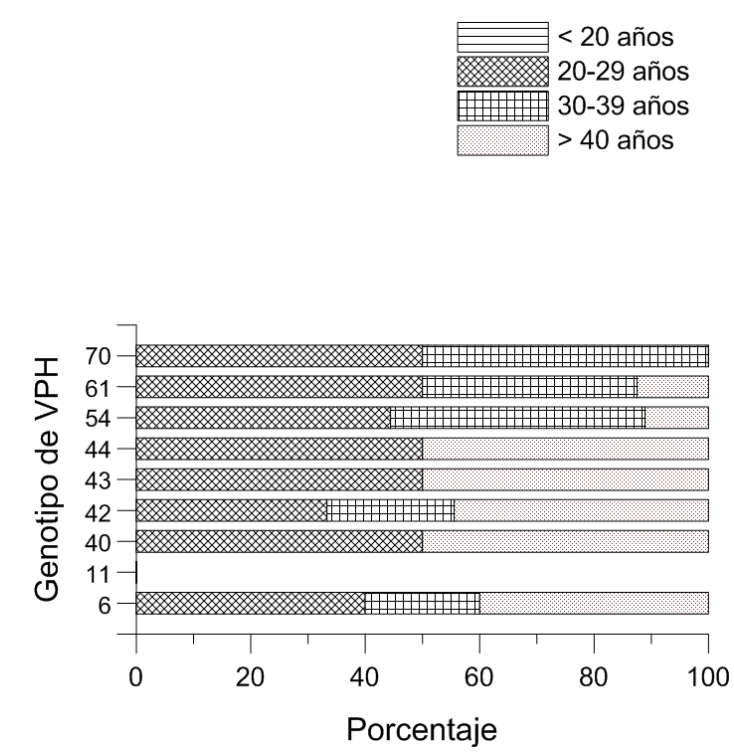

Figura 6. Relación de los genotipos de bajo riesgo del papiloma virus humano con grupos de edad.

El porcentaje de los genotipos es variable en los diferentes grupos de edad, no hay diferencias estadísticamente significativas (véase Figs 5 \& 6). El genotipo 11 no se detectó en ninguno de los grupos etarios. El 7\% de las mujeres presentan atípia escamosas de significación indeterminada (ASCUS) y el $1.8 \%$ lesiones intraepiteliales de bajo grado (LIEBG). Conforme se incrementa la edad aumenta la prevalencia del ASCUS, siendo mayor en el grupo de 40 años y más (3.4\%) (véase Fig. 7). En el grupo de menores de 20 años no se ha detectado ninguna de las dos lesiones diagnosticadas por Papanicolaou.

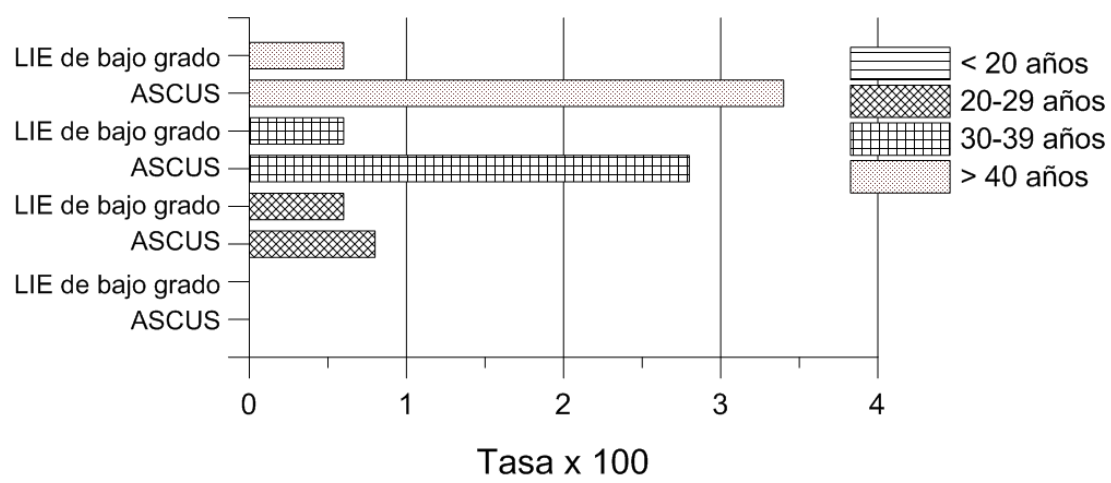

Figura 7. Relación entre la prevalencia de ASCUS y lesiones intraepiteliales del cáncer uterino con la edad.

Vacuna Cervarix vacuna utilizada a nivel mundial para prevenir el cáncer del cuello del útero evita la replicación de los genotipos 16 y 18. Al relacionar estos genotipos con los encontrados en el estudio, se determina que la prevalencia del genotipo 16 es de $2.2 \%$ y del 18 , el $0.60 \%$, con lo cual se concluye que la protección para las mujeres con vida sexual de 17 a 50 años, que residen en los 14 cantones de la provincia del Azuay, es del 2.8\%. 


\section{DISCUSIÓN}

La prevalencia del papiloma virus humano (VPH) en muestras aleatorizadas cérvico uterinas de mujeres con vida sexual, que residen en los 14 cantones de la provincia del Azuay, es de 25.6\%, mucho menor a los resultados del estudio, también aleatorizado, realizado en mujeres de las 14 parroquias urbanas de la ciudad de Cuenca que es del 50.3\% (Cárdenas et al., 2014). Hay otros estudios intrahospitalarios no aleatorizados realizados en el país, como el de Cuenca (SOLCA, 2009) que muestran una prevalencia de $37.1 \%$, la investigación en Santa Elena Guayas-Ecuador 24.2\% (Brown et al., 2009) y el realizado en el hospital Metropolitano de Quito que es de 67.7\% (GonzálezAndrade \& Sánchez, 2009). La prevalencia de HPV en diferentes países del mundo es variable como lo demuestran los artículos científicos revisados: en China 15.3\% (Zhao et al., 2014), en Portugal 28.3\% (Mazarico et al., 2014); Sur de Italia 45.9\% (Menegazzi et al., 2009); en Carolina del Sur 32\% (Banister et al., 2013); y en España 3.4-17\% (Diestro Tejeda et al., 2007). En investigaciones latinoamericanas, la prevalencia del PVH también es variable: México 37.2\% (Hernández-Giron et al., 2005); Colombia 14.8\% (Ortiz et al., 2004); Chile 84.8\% (Melo et al., 2014), Perú 50.6\% (Montaño et al., 2011); población indígena del Amazonas Venezolano 35\% (Nicita et al., 2010); Trinidad 40.6\% (Andall-Brereton et al., 2011); aborígenes de la etnia Pilagá Formosa - Argentina 46.7\% (Deluca et al., 2012); Argentina 41\% (Sijvarger et al., 2006); Hospital Clínico Regional de Valdivia Chile 24\% (Barrientos et al., 2006). Como se puede apreciar, la prevalencia del HPV es muy variable entre un país y otro; la prevalencia más baja encontrada en esta revisión bibliográfica corresponde a Colombia con el $14.8 \%$ y la más alta Chile con el $84.8 \%$.

Los VPH de alto riesgo representan el $20.40 \%$ con un IC de 12.58-28.22; los VPH de bajo riesgo el 20\% con un IC de 13.07-26.93; Las mujeres que tienen tanto los virus de alto, como de bajo riesgo representan el 7.8\% con in IC de 5.45-10.15; el 6.6\% de las mujeres presentan infección con más de un genotipo viral. Los genotipos de alto riesgo oncogénicos identificados en el presente estudio, en orden descendente son los siguientes: el 66 (3.2\%), 68 (2.8\%), 16 (2.2\%), 59 (2\%), 31 (1.8\%), 39 (1.6\%), 33 (1.4\%), 53 y 51 (1.2\%); los demás con $1 \%$ y menos; al comparar estos resultados con otros realizados a nivel nacional, hay similitud con la investigación del Hospital Metropolitano de Quito, ya que los genotipos más comunes encontrados fueron también el 66 (4.8\%) y 16, 31 (2.4\% cada uno); en la investigación de Santa Elena Guayas (Ecuador), los genotipos más frecuentes de alto riesgo fueron 16, 52, 58 y 59 (Brown et al., 2009) dos genotipos, de ellos, también presentes en la investigación actual, el 16 y el 59. En Cuenca (Ecuador) (Sánchez et al., 2008), en una población de 727 mujeres con ASCUS y con lesiones intraepiteliales, encuentran que el genotipo más frecuente es VPH 16 (31.27\%), seguido del 58 (27.21\%), 52 (21.65\%), 56 (17.57\%), 51 (16.75\%), 66 (15.13\%); y $18(6.34 \%)$. Estos genotipos difieren a los encontrados en el presente estudio, a excepción del genotipo 16 y 51 . Los genotipos de bajo riesgo más frecuentes son: 42 y 54 ( $2 \%$ cada uno de ellos) el $61(1.6 \%), 6(1 \%)$ y $44(0.6 \%)$. Al comparar este resultado con un estudio similar realizado en mujeres de la ciudad de Cuenca (Ecuador), los genotipos más frecuentes son: 42, 43, 6, 11, 44, de los cuatro hay dos que están presentes tanto en la ciudad de Cuenca como en los cantones de la provincia del Azuay y son el 43 y 44. En la investigación realizada en SOLCA, los genotipos de bajo riesgo encontrados son el 43 y 44, iguales a los encontrados en las mujeres de la provincia del Azuay; en Santa Elena, Guayas (Ecuador) los genotipos identificados son el 62, 71, 72 y 83 y en el Hospital Carlos Andrade Marín de la ciudad de Quito el genotipo 19; ninguno de ellos se encontró en el presente estudio. La diferente prevalencia con la que se presenta el VPH entre un país a otro o entre regiones de un mismo país, responde posiblemente a situaciones de orden cultural, social, económico, sanitario, así como a las diferentes técnicas diagnósticas utilizadas para la detección del virus, a los métodos de investigación utilizados, a la aleatorización o no de las muestras de estudio, como también a que si estas fueron obtenidas en población general o en pacientes que asisten a consulta externa en centros de salud u hospitales.

Con respecto a las lesiones pre-malignas detectadas mediante el examen de Papanicolaou, se encuentra en la población total una prevalencia de 7\% de ASCUS y de 1.8\% de LIE de bajo grado; en la distribución por grupos de edad el ASCUS se incrementa con la edad; por lo tanto, en el grupo de 
20 a 29 años, la prevalencia es de $0.8 \%$; en el grupo de 30 a 39 años, $2.8 \%$ y en el de 40 años o más, $3.4 \%$. La prevalencia del LIEBG es igual en los tres grupos, $0.6 \%$. No conocemos resultados de estudios aleatorizados realizados en cantones que tengan iguales objetivos con la presente investigación, razón, por lo que no podemos compararlos.

Como objetivo de la investigación también se plantea la necesidad de buscar la relación entre los genotipos del VPH encontrados en la investigación con los genotipos que evitan las dos vacunas Gardasil y Cervarix. Considerando que no hay un grado de intensidad de asociación entre estas dos variables, se expresa solamente una relación entre ellas. La vacuna Cervarix, utilizada en el país por el Ministerio de Salud Pública evita los genotipos 16 y 18, por tal motivo las pacientes vacunadas presentarían protección solo para las que tienen estos genotipos de alto riesgo, que se ha detectado en apenas el 2.8\% de la población general. Conociendo los resultados del estudio realizado en SOLCA en el año 2006, la vacuna protegería al 8.5\%, y en la muestra de pacientes del Hospital Metropolitano de Quito en el año 2006, protegería en el 3.2\%. La protección de la vacuna Gardasil para los genotipos benignos 6 y 11 protegería a las mujeres de los cantones de la provincia del Azuay en el 1\%, para la población estudiada por SOLCA 0\%, y para la población del Hospital Metropolitano 10.4\%.

La comparación de las conclusiones propias con la de otros autores es posible realizar únicamente con el estudio efectuado en las mujeres de las 14 parroquias urbanas del cantón Cuenca, ya que los dos estudios son aleatorizados y comparten los mismos objetivos específicos y metodológicos. La prevalencia de todos los genotipos del papiloma virus en la investigación actual es del $25.6 \%$ y la de la investigación en el cantón Cuenca es del 50.3\%. Estimamos que esta diferencia está relacionada por la variabilidad de la distribución genotípica en las poblaciones de acuerdo al lugar y tiempo, como se puede observar en los resultados distintos, sobre prevalencia, en otras investigaciones nacionales e internacionales, que constan en la introducción del presente informe. Lo nuevo en la presente investigación constituyen los resultados diferentes en la prevalencia de los genotipos en poblaciones femeninas sexualmente activas de la provincia del Azuay, lo que permite concluir, que los métodos de diagnóstico del papiloma virus deben seguir protocolos que consideren la prevalencia de los genotipos del papiloma virus, que ineludiblemente deben ser conocidos. Además se concluye que la protección de las vacunas es insuficiente, en las poblaciones investigadas, por cuanto la vacuna Cervarix solo evita 2 genotipos y el Gardasil 4 genotipos, que no corresponden a los genotipos que caracteriza a las poblaciones de mujeres con vida sexual activa de la provincia del Azuay. Se deduce, por lo tanto, que las vacunas deben ser elaboradas para ser utilizadas de acuerdo con las mayores prevalencias de cada región, es decir considerando las características poblaciones de cada lugar, por lo tanto, deben ser selectivas.

De acuerdo con lo expuesto se puede colegir que es indispensable conocer la prevalencia de los genotipos que se encuentran en los tumores benignos (condilomas acuminados) o malignos (cáncer de cuello uterino) causados por el papiloma virus, estudiando muestras obtenidas por biopsia o procedimientos quirúrgicos, para conociendo sus resultados elaborar protocolos para la prevención, diagnóstico y tratamiento de las enfermedades causadas por el papiloma virus, con base a los resultados de las investigaciones existentes y en caso de no existirlas, iniciar de inmediato este tipo de investigaciones.

Es este artículo no se exponen los resultados de los factores de riesgo estudiados para la infección por papiloma virus humano, por cuanto, son muy extensos y serán publicados en un nuevo artículo que se publicará en una revista indexada.

\section{CONCLUSIONES}

Los resultados de la investigación confirman la hipótesis planteada, que la infección por el papiloma virus humano es frecuente en las mujeres con vida sexual activa que habitan en los 14 cantones de la provincia del Azuay, puesto que el 25.6\% de mujeres lo padecen. Los genotipos de bajo riesgo de mayor prevalencia a nivel mundial son el 6 y el 11; en el presente estudio, el genotipo 6 apenas se encuentra en el $1 \%$ de las mujeres, y el 11 en ninguna; los genotipos de bajo riesgo más prevalente son: el 42 y el 54 con el $2 \%$ cada uno. Los genotipos de alto riesgo de mayor prevalencia a nivel 
mundial son el 16 y el 18; en la presente investigación, la prevalencia del genotipo 16 es de $2.2 \%$ y del 18 el $0.6 \%$. Por lo tanto son otros los genotipos de alto riesgo de mayor prevalencia en nuestro medio, el 66 con el $3.2 \%$ y el 68 con $2.8 \%$. Es motivo de preocupación que los genotipos de alto riesgo tienen una prevalencia mayor que los de bajo riesgo, lo cual debe ser considerado por las autoridades sanitarias para emprender acciones preventivas y por los investigadores para profundizar las investigaciones en miras a identificar si los genotipos de alto riesgo encontrados son o no los causantes del cáncer cérvico-uterino en las mujeres de la provincia.

En relación a las lesiones intraepiteliales detectadas por el examen de Papanicolaou, se encontró una prevalencia de 7\% de ASCUS y de 1.8\% de LIE de bajo grado. El ASCUS se incrementa con la edad, en tanto que la prevalencia del LIE de bajo grado es igual en los tres grupos, $0.6 \%$. Al relacionar la prevalencia de los genotipos del papiloma virus de alto y bajo grado oncogénico humano encontrado en las mujeres en estudio, con los genotipos que evita la vacuna, CERVARIX (genotipo 16-18) que se encuentra aplicando el MSP en el país, se concluye que la vacuna apenas lograrían proteger al 2.8\% de la población. Son necesarias nuevas investigaciones para demostrar si los genotipos de alto riesgo encontrados en el presente estudio son los causantes del cáncer cérvicouterino en las mujeres de la provincia.

Al haber aplicado un rigor metodológico durante toda la investigación y al ser los resultados del estudio producto de una muestra aleatorizada, el impacto médico, oncológico y social es relevante ya que se pueden extrapolar los resultados a todas las mujeres con vida sexual activa de 17 a 50 años, que residen en los 14 cantones de la provincia del Azuay. La conclusión innovadora y por lo tanto original, estriba en que la distribución de los genotipos de alto y bajo riesgo oncogénico en las mujeres con vida sexual activa de los 14 cantones de la provincia del Azuay, difiere sustancialmente de un cantón a otro, variabilidad que se puede también observar en los resultados diferentes de otras investigaciones nacionales e internacionales, y que constan en la introducción del presente informe. Las prevalencias de los genotipos en las poblaciones femeninas de la provincia del Azuay, permite concluir, que los métodos de diagnóstico del papiloma virus deben sustentarse en protocolos que consideren la prevalencia de los genotipos del VPH y que obligatoriamente deben ser conocidos. Se concluye, además, que la protección de las vacunas es pequeña, en las poblaciones investigadas, por lo que la vacuna Cervarix solo evita 2 genotipos y el Gardasil 4 genotipos, que desafortunadamente no se relacionan con los resultados de la variabilidad de genotipos encontrados en lasmujeres de la provincia del Azuay. Por lo expuesto, se teoriza y recomienda, que las vacunas deben ser producidas y utilizadas para evitar los genotipos de mayor prevalencia en cada lugar, es decir, se debe conocer previamente las prevalencias genotípicas en las diferentes regiones para elaborar y aplicar las vacunas.

Considerando el desarrollo futuro del diagnóstico y tratamiento de las lesiones benignas y del cáncer de cuello uterino, causados por el papiloma virus humano, es indispensable e imperativo conocer la prevalencia de los genotipos en los tumores benignos (condilomas acuminados) o malignos (cáncer de cuello uterino), utilizando muestras histológicas extraídas por biopsia o procedimientos quirúrgicos, para conociendo aquellos resultados, elaborar protocolos para la prevención, diagnóstico y tratamiento de las enfermedades causadas por este virus, con base de los resultados de las investigaciones existentes y de otras que deben realizarse de forma inmediata.investigaciones.

\section{RECONOCIMIENTO}

Agradecemos al Director de la Dirección de Investigación de la Universidad de Cuenca Ing. Jaime Bojorque Íñeguez PhD, a su personal administrativo, a la Dra. Rocío Murillo, Anatomo Patóloga, a la Licenciada Jenny Álvarez Citopatóloga, a la Licenciada Lourdes Viñanzaca Auxiliar del Laboratorio de Biología Molecular de la Facultad de Ciencias Médicas y de una manera especial a los estudiantes de la carrera de laboratorio clínico: Dorys Galarza, José Ortiz, Catalina Torres, Fabiola Calle, Viviana Guallpa, Sandra Reinoso, Diana Barbecho, Mayra Viñanzaca y Viviana Caiminagua; a los médicos ginecólogos del MSP que laboran en los hospitales cantonales de la provincia del Azuay: Drs. Milton 
Zambrano, Wilson Valencia, Mery Orellana, Marilú Ñauta, Girón: Dr. Wilson Wuashco, Fabián López, Eva Astudillo, Julio Cárdenas, Carlos Vázquez, Patricia Quezada, Lourdes Solórzano y Alexandra Usiña, Mayra Campoverde, Marco Núñez, Glenda Chiriboga, Juan Romero, Alba Maita, Diego Vega, María Rosa Sánchez. Un agradecimiento especial al Dr. Marco Freire, Jefe de la Zona 6 de Salud, al personal administrativo de la Dirección de Salud del Azuay y a los Directores de los hospitales de los 14 cantones de la provincia del Azuay.

\section{BIBLIOGRAFÍA}

American Cancer Society; 2015. Cáncer del cuello uterino: factores de riesgo. Last Medical Review: 10/30/2014; Last Revised: 2/26/2015. Copyright American Cancer Society, pp. 4-9. Disponible en: http://www.cancer.org/acs/groups/cid/documents/webcontent/002288-pdf.pdf; consultado el 3 de marzo de 2015.

Andall-Brereton, G.M., F. Hosein, R.A. Salas, W. Mohamed, M.A. Monteil, V. Goleski, A. Severini, S.M.M. Quesnel, C.V.F. Carrington, L.L. Boodram, E. Boisson, P.E. Akpaka, R.C. Paul, 2011. Human papillomavirus genotypes and their prevalence in cohort of women in Trinidad. Rev. Panam. Salud Publica, 29(4), 220-226.

Barrientos, B., 2013. Identificación de virus papiloma humano asociado a citología ASCUS de cérvix uterino en mujeres del Hospital Clínico Regional Valdivia. Páginas 12-50. Disponible en http://cybertesis.uach.cl/tesis/uach/2006/fcb275i/doc/fcb275i.pdf; consultado el 28 agosto de 2013.

Baseman, J.G., L.A. Koutsky, 2005. The epidemiology of human papillomavirus infections. J. Clin. Virol., 32S, S16-24.

Banister C.E., A.R. Messersmith, H. Chakraborty, Y. Wang, L.B. Spiryda, S.H. Glover, L. Pirisi, K.E. Creek, 2013. HPV prevalence at enrollment and baseline results from the Carolina Women's Care Study, a longitudinal study of HPV persistence in women of college age. Int. J. Wom. Health, 5, 379-388.

Biocáncer Research Journal, 2010a. Instituto Canario de la investigación del Cáncer. España. ISS 1697-6452. Disponible en http://www.biocancer.com/journal/995/42-estructura-genica; consultado el 10 de marzo de 2015.

Biocáncer Research Journal, 2010b. Instituto Canario de la investigación del Cáncer. España 2010. ISS 1697-6452. Disponible en http://www.biocancer.com/journal/372/3-etiologia; consultado el 10 de marzo de 2015.

Brown, C.R., M.L. Leon, K. Muñoz, A. Fagioni, L.G. Amador, B. Frain, W. Tu, B. Qadadri, D.R. Brown, 2009. Human papillomavirus infection and its association with cervical dysplasia in Ecuadorian women attending a private cancer screening clinic. Braz. J. Med. Biol. Res., 42(7), 629-36.

Bruni, L., M. Díaz, X. Castellsague, E. Ferrer, F.Bosch, S. de Sanjose. 2010. Cervical Human Papillomavirus Prevalence in 5 continents: Meta-analysis of 1 million women with normal cytological findings. J. Infect. Dis., 202(12), 1789-1799.

Burk, R., D. Gloria, F. Ho, L. Beardsley, M. Lempa, M. Peters, R. Bierman. 1996; Sexual behavior and partner characteristics are the predominant risk factors for genital human papillomavirus infection in young women. J. Infect. Dis., 174(4), 679-689.

Cárdenas, O., J. Cabrera, A. Campoverde, 2014. A prevalencia de genotipos del papiloma virus en mujeres de Cuenca. Revista de la Facultad de Ciencias Médicas de la Universidad de Cuenca, 32(1), 6-15. Disponible en http://dspace/ucuenca.edu.ec/handle/123456789/20038.

Deluca, G.D., H.M. Marin, E. Schelover, E.M. Chamorro, L. Vicente, M. Albhom, J.M. Alonso, 2006. Infección por Chlamydia trachomatis y papillomavirus en mujeres con alteraciones citohistologicas de cuello uterino. Medicina (Buenos Aires), 66, 303-306. Disponible en http://www.scielo.org.ar/pdf/ medba/v66n4/v66n4a03.pdf. 
Deluca, G.D., J. Basiletti, J.V. González, N. Díaz Vásquez, R.H. Lucero, M.A. Picconi, 2012. Human papillomavirus risk factors for infection and genotype distribution in aboriginal women from northeren Argentina. Medicina (Buenos Aires), 72, 461-466. Disponible en http://www.scielo.org.ar/ pdf/medba/v72n6/v72n6a03.pdf.

De Guglielmo, Z., M. Ávila H., M. Correnti, D. Veitía, M. Cavazza, 2008. Evaluación, mediante $\mathrm{RCP}$, de la infección por el virus de papiloma humano en muestras de pacientes con diagnóstico clínico o citológico. Rev. Obstet. Ginecol. Venez., 68(4), 240-247. Disponible en http://www.scielo.org.ve/ pdf/og/v68n4/art06.pdf.

Diestro Tejeda, M.D., M. Serrano Velasco, F. Gómez-Pastrana, 2007. Cáncer de cuello uterino. Estado actual de las vacunas frente al virus del papiloma humano (VPH). Oncología, 30(2), 4259.

Fedrizzi, E.N., 2011. Epidemiologia da infecção genital pelo HPV Epidemiology of the genital HPV infection. Artigo de revisão. Rev. Bras. Pat. Trato. Gen. Inf., 1(1), 3-8. Disponible en http://projetohpv.com.br/projetohpv/wp-content/uploads/2011/03/RBPTGI-Epidemiologia, pdf; Consultado el 28 de marzo de 2015.

Franco E.L., L.L. Villa, J. Sobrinho, J. Prado, M.C. Rousseau, M. Désy, T. Rohan, 1999. Epidemiology of acquisition and clearance of Cervical Human Papillomavirus infection in women from a high-risk area for cervical cancer. J. Infect. Dis., 180(5), 1415-1423.

González-Andrade, F., D. Sánchez, 2009. HPV genotyping in anogenital abnormal samples of Ecuadorian women. Cancer Biomark., 5(4), 225-232.

Hernández-Giron, C., J.S. Smith, A. Lorincz, E.A. Cháidez, E. Lazcano, M. Hernández-Ávila, J. Salmerón, 2005. Prevalencia de infección por virus de papiloma humano (VPH) de alto riesgo y factores asociados en embarazadas derechohabientes del IMSS en el estado de Morelos. Salud pública Méx., 47(6), 423-429.

INEC, 2009. Anuario de nacimientos y defunciones. Instituto Nacional de Estadística y Censos, Quito, Ecuador. Disponible en http://www.ecuadorencifras.gob.ec/anuario-de-nacimientos-ydefunciones/.

Instituto Nacional del Cáncer de los Estados Unidos, 2014. Pruebas de Papanicolaou y del virus del Papiloma humano (VPH): ¿Cómo se informan los resultados de los exámenes de detección del cáncer de cérvix?. Disponible en http://www.cancer.gov/espanol/tipos/cuello-uterino/hojainformativa-prueba-pap-vph; consultado el 1 de abril de 2015.

Kolnikova, G., M. Ondrusova, V. Repiska, R. Drobna, P. Marinova, I. Meciarova, J. Rampalova, F. Ondrias, 2014. Current possibilities of cervical precancerous lesions screening in Slovakia: prevalence of high risk human papillomavirus in patients with cytological diagnoses of atypical squamous cells of unknown significance. Bratisl. Lek. Listy., 115(8), 469-73.

Mazarico, E., M.D. Gómez-Roig, J. Miñano, L. Cortes, E. Gonzalez-Bosquet, 2014. Relationship of human papilloma virus multiple genotype infection with patient's age and type of cervical lesion. Eur. J. Gynaecol. Oncol., 35(4), 378-381.

Melo, A., A.M. Vásquez, A. Adana, M. Matamala, T. Pino, P. Guzmán, R. Hoffstetter, C. Ili, P. Brebi, J.C. Roa, 2014. Genotipificación del virus papiloma humano en mujeres bajo 25 años de edad participantes del Programa Nacional del Cáncer Cérvico-uterino en la Región de la Araucanía, Chile. Rev. chil. infectol., 31(5), 542-548. Disponible en http://www.scielo.cl/pdf/rci/v31n5/art05.pdf; consultado el 10 de enero de 2015.

Menegazzi, P., L. Barzon, G. Palù, E. Reho, L. Tagliaferro, 2009. Human papillomavirus type distribution and correlation with cyto-histological patterns in women from the south of Italy. Infect. Dis. Obstet. Gynecol., 2009, 4 pp. Disponible en http://www.hindawi.com/ journals/idog/2009/198425/; consultado el 15 abril de 2014.

Monk, B.J., D.J. Wiley, 2004. Human papillomavirus infections. Cancer, 100(2), 225-227.

Moscicki, A.B., S. Shiboski, J. Broering, K. Powell, L. Clayton, N. Jay, T.M. Darragh, R. Brescia, S. Kanowitz, S.B. Miller, J. Stone, E. Hanson, J. Palefsky, 1998. The natural history of human 
papilloma virus infection as measured by repeated DNA testing in adolescent and young women. J. Pediatr., 132(2), 277-284.

Muñoz, N., F. Méndez, H. Posso, M. Molano, A.J. van den Brule, M. Ronderos, C. Meijer, A. Muñoz, 2003. Incidence, duration, and determinants of cervical human papillomavirus infection in a cohort of Colombian women with normal cytological results. J. Infect. Dis., 190(12), 2077-2087.

Nicita, G., A. Reigosa, J. Torres, C. Vázquez, Y. Fernández, M. Álvarez, N. Núñez, M. Magris, 2010. Infección por virus del papiloma humano (VPH) en una población indígena del Amazonas venezolano. Salus online, 14(1), 51-59. Disponible en http://salus-online.fcs.uc.edu.ve/ vph_indigena_amazonas.pdf; consultado el 24 agosto de 2013.

Ojeda, M. 2010. Human papillomavirus: From biology to the clinic. Actas de Reuniones Clínicas. Departamento de Medicina, Hospital Clínico Universidad de Chile. Disponible en http://www.medwave.cl/link.cgi/medwave/Reuniones/4619?ver=sindiseno; consultado el 4 de enero 2015.

Ortiz Serrano, R., C.J. Uribe Pérez, L.A. Díaz Martínez, Y.R. Dangond Romero, 2004. Factores de riesgo para cáncer de cuello uterino. Revista Colombia de Obstetricia y Ginecología, 55(2), 146160. Disponible en http://www.scielo.org.co/pdf/rcog/v55n2/v55n2a07.pdf; consultado el 18 de enero de 2015.

Rocha, L., 2014. Infecciones de transmisión sexual: Papiloma Virus Humano. Depto. Biología Molecular y Biotecnología, Instituto de Investigaciones Biomédicas, UNAM. Disponible en http://www.facmed.unam.mx/deptos/microbiologia/virologia/infecciones-transmisionsexual.html; consultado el 10 de enero de 2015.

Sijvarger, C.C., J.V. González, A. Prieto, A.G. Messmer, M.C. Mallimaci, V.L. Alonio, A.R. Teyssié, M.A. Picconi, 2006. Epidemiología de la infección cervical por virus papiloma humano en Ushuaia, Argentina. Revista Argentina de Microbiología, 38, 19-24. Disponible en http://www.scielo.org.ar/ pdf/ram/v38n1/v38n1a05; consultado el 17 de diciembre de 2014.

SOLCA, 2007. Quinto Informe de Incidencia de Cáncer en el Cantón Cuenca. SOLCA, Cuenca, Ecuador. Sitio web: http://www.institutodelcancer.med.ec/index_archivos/registro_tumores.htm.

Sánchez, M., F. Calderón, D. Martínez, J. Ugalde, 2008. Frecuencia de los diferentes tipos virales en pacientes del Instituto del Cáncer SOLCA CUENCA 2008-2009. Instituto del Cáncer SOLCACuenca. Disponible en http://www.instituto delcancer.med.ec/index_archivos/informativo.htm; consultado el 13 de enero de 2015.

Tamay, L, C. Ibarra, C Velasquillo. 2013. Fundamentos de la reacción en cadena de la polimerasa (PCR) y de la PCR en tiempo real. Laboratorio de Biotecnología del Centro Nacional de Investigación y Atención a Quemados. Instituto Nacional de Rehabilitación (INR), México, D.F., Medigraphic, 2(2), 70-78. Disponible en http://www.medigraphic.com/pdfs/invdis/ir2013/ir132d.pdf; consultado el 21 de febrero de 2015.

Zhao, F-H., F-C. Zhu, W. Chen, J. Li, Y-M. Hu, Y. Hong, Y-J. Zhang, Q-J. Pan, J-H. Zhu, X. Zhang, Y. Chen, H. Tang, H. Zhang, C. Durand, S.K. Datta, F. Struyf, D. Bi, 2014. Baseline prevalence and type distribution of human papillomavirus in healthy Chinese women aged 18-25 years enrolled in a clinical trial. Int. J. Cancer, 135(11), 2604-2611. 